\title{
BMJ Global Health Achieving high-quality universal health coverage: a perspective from the National Health Service in England
}

\author{
Rocco Friebel, ${ }^{1,2}$ Aoife Molloy, ${ }^{3}$ Sheila Leatherman, ${ }^{4}$ Jennifer Dixon, ${ }^{5}$ \\ Sebastian Bauhoff, ${ }^{2,6}$ Kalipso Chalkidou ${ }^{2,7}$
}

\begin{abstract}
To cite: Friebel R, Molloy A, Leatherman S, et al. Achieving high-quality universal health coverage: a perspective from the National Health Service in England. BMJ Glob Health 2018;3:e000944. doi:10.1136/ bmjgh-2018-000944
\end{abstract}

Handling editor Seye Abimbola

Received 8 May 2018

Revised 17 October 2018

Accepted 28 0ctober 2018

Check for updates

C Author(s) (or their employer(s)) 2018. Re-use permitted under CC BY-NC. No commercial re-use. See rights and permissions. Published by BMJ.

${ }^{1}$ Department of Health Policy, The London School of Economics and Political Science London, UK

${ }^{2}$ Center for Global Development, Washington, District of

Columbia, USA

${ }^{3}$ Department of Surgery and Cancer, Imperial College London, London, UK

${ }^{4}$ Gillings School of Public Health, University of North Carolina, Chapel Hill, North Carolina, USA

${ }^{5}$ The Health Foundation, London, UK

${ }^{6}$ Department of Global Health and Population, Harvard T.H. Chan School of Public Health, Boston, MA, USA

${ }^{7}$ School of Public Health, Imperial College London, London, UK

Correspondence to

Dr Rocco Friebel;

r.friebel@Ise.ac.uk

\section{ABSTRACT}

Governments across low-income and middle-income countries have pledged to achieve universal health coverage by 2030 , which comes at a time where healthcare systems are subjected to multiple and persistent pressures, such as poor access to care services and insufficient medical supplies. While the political willingness to provide universal health coverage is a step into the right direction, the benefits of it will depend on the quality of healthcare services provided. In this analysis paper, we ask whether there are any lessons that could be learnt from the English National Health Service, a healthcare system that has been providing comprehensive and high-quality universal health coverage for over 70 years. The key areas identified relate to the development of a coherent strategy to improve quality, to boost public health as a measure to reduce disease burden, to adopt evidence-based priority setting methods that ensure efficient spending of financial resources, to introduce an independent way of inspecting and regulating providers, and to allow for task-shifting, specifically in regions where staff retention is low.

\section{INTRODUCTION}

Healthcare systems in low-income and middle-income countries (LMICs) are subject to multiple and persistent pressures, often the result of weak institutions, corruption and difficulties in creating and retaining all of the building blocks of a healthcare system. ${ }^{1}$ This can lead to poor access to healthcare services, inadequate drugs and medical supplies, and labour force shortages. These pressures exist at a time when universal health coverage (UHC) is a common goal across the world, presenting an increased challenge, especially for lower resourced countries. ${ }^{2}$

The concept of UHC is now considered to go beyond the three dimensions of population, services and costs, ${ }^{3}$ with an increasing focus being placed on ensuring a level of quality that helps to improve the health of the service seeker. Thus, in the context of LMICs, quality refers to the access of safe
Summary box

- The value of universal health coverage to populations, governments, and payers depends on the quality of healthcare services provided, requiring a coherent strategy that ensures expansion of services that are safe to use without inflicting harm to patients.

- Countries should adopt strategies for priority setting based on robust evidence-based methods to avoid waste of resources. Low-income and middle-income countries can learn and borrow from the National Institute for Health and Clinical Excellence, for example, through the International Decision Support Initiative.

- Boosting public health is a prerequisite to a well-functioning healthcare system. Ensuring a functioning primary care system to prevent avoidable hospitalisation is critical and a priority for the population over expensive specialised care.

- An independent way of inspecting and regulating providers on the quality of care provided is important, with transparent publishing of data on performance.

and effective evidence-based treatments, in a timely manner, and without discrimination by socioeconomic and financial status. Achieving high-quality UHC is likely to be expensive to government and other payers, depending on how the UHC is designed, but with the benefits to individuals, populations and payers reliant on the quality of healthcare provided. Here we ask whether there are any lessons for improvement of quality that could be learnt from an existing UHC healthcare system like the English National Health Service (NHS).

\section{WHY IS THE EXPERIENCE FROM THE ENGLISH NHS RELEVANT FOR LMICS?}

The NHS has been providing UHC to the population of England for over 70 years. While UHC can take several forms and can be achieved through different funding mechanisms, for example, through a social health 
insurance scheme employed in Germany, the Netherlands and Switzerland, the NHS is almost entirely funded by government (the 'single payer') through redistribution of tax revenue, similar to the health system in Italy and Spain. However, the NHS has been unique on the universalism it offers to its citizen, because it provides comprehensive benefits to all residents, free at the point of access regardless of ability to pay, and with next to no patient charges. It operates under a fixed budget that requires strict measures for cost and quality control, with constraining healthcare costs being a challenge in the face of increasing demands, not least from an ageing population and multiple comorbidities from chronic non-communicable disease (NCDs). This is similar to many LMICs, where public healthcare services are provided by the government and confronted with substantial challenges arising from demographic changes and people living with chronic conditions. For example, half of the total burden of disease in India is the result of NCDs, ${ }^{4}$ and similarly in many sub-Saharan African countries, demand for healthcare is increasingly shifting away from infectious diseases towards chronic conditions like diabetes and cardiovascular disease. ${ }^{5}$

The NHS is unusual as a UHC system, because the government is the single payer and owns almost all providers operating within the NHS. About $10 \%$ of the NHS budget is spent on non-NHS providers (mainly providers of community services not hospitals), and importantly there is a set system of national prices (the national tariff) covering about $60 \%$ of services. NHS staff is contracted to the NHS, including doctors who are salaried. Primary care practitioners are self-employed but almost all work $100 \%$ under contract to the NHS. These are important and effective methods of cost control in what could be seen as a government-funded, free, and open-ended system. Establishing UHC in LMICs will require incremental increases in public expenditure, and cost control is a key area of focus for governments to ensure highest return on investment. Mismanagement and ineffective investment decisions can result in cost escalation without translation into better healthcare for populations.

The NHS regularly tops polls as the most important issue facing Britain. What is clear is that the public strongly support the security of UHC; employers are not burdened by mandatory health taxes as in the case of employer-funded systems. Though most people living in England were dissatisfied with the way the NHS operated in 1997, public perception has since greatly improved, peaking at a $70 \%$ by $2010,{ }^{6}$ and reaching $57 \%$ in $2017 .{ }^{7}$ Rises in satisfaction have been observed during a period with enhanced government funding and attention to improve healthcare quality, particularly since 2000 . The continuous efforts, on the part of different governments, show that the political willingness to drive healthcare improvements is essential. The same principle applies to LMICs. ${ }^{8}$ Political willingness, determination and vision are paramount, and progress has been made for example through such global and national-level initiatives as the 2015 United Nations resolution for UHC, the introduction of the 2017 National Health Policy in India, or Rwanda's Vision 2020.

\section{EXAMPLES OF STRENGTHENING HEALTHCARE QUALITY IN THE ENGLISH NHS: WHAT ARE SOME POTENTIAL LESSONS FOR LMICS?}

The NHS is well known internationally as a system in which a lot of new initiatives to improve quality are tested, as recognised by the Organisation for Economic Co-operation and Development in its 2016 review of healthcare systems. ${ }^{9}$ While the list of initiatives is impressive, more work needs to be done on developing a coherent strategy shown to improve quality. ${ }^{10}$ Adopted initiatives include tighter accountability for quality in providers by clinicians through a process known as "clinical governance' from 1998, to a national systematic approach to developing evidence-based clinical guidelines for new treatments (through the National Institute for Health and Clinical Excellence (NICE)), to regulation of quality through inspection and publicly reported ratings, to performance-related financial incentives for quality. Though admittedly a very different context and level of resourcing, all of these contain lessons for healthcare systems in LMICs. There have been demonstrable benefits but, with varying levels of investment required, and with varying risks and unintended consequences, examples of which are illustrated here.

\section{Prevention}

To improve primary disease prevention, England has introduced a number of strict polices, ${ }^{11}$ such as raising the minimum age for the purchase of tobacco products, imposing minimum unit pricing for alcohol, or introducing a soft drinks industry levy. A public smoking ban, introduced in 2007, has resulted in significant reductions in smoking-related heart disease $(-20.8 \%)$ and stroke $(-14.5 \%) .{ }^{12}$ Due to a system of local government, many councils can use planning and other regulations to act in the absence of national government action, for example, in not allowing fast and junk food outlets to set up outside schools. This action has required political leadership in the face of lobbying from some well-resourced interest groups, and in some cases cross-ministry collaboration. Evidence to support the case for change is critical, but overwhelmingly the issue is political leadership. Too often LMICs have been unable to overcome these obstacles to take action to adopt prevention policies, such as those evidence-based 'best-buy' interventions recommended by WHO. ${ }^{13}$ However, there are positive examples where governments have introduced primary disease prevention programmes, for instance, the 2017 alcohol taxation and drink-driving laws in Malawi, ${ }^{14}$ or a 2009 obesity prevention programme that addressed food formulation and advertising regulations for children in Brazil. ${ }^{15}$ 
Policy makers in the NHS have long identified secondary prevention as a key opportunity to prevent the occurrence of costly complications. For instance, primary care practitioners are financially incentivised to carry out a range of services such as wellness checks, vaccinations and be proactive in structured chronic disease management (ie, structured disease management refers to a framework of evidence-based best practice to guide the clinician). An example of the latter is the care of patients with diabetes, which includes regular assessments of body mass index, HbAlc level and foot examinations. ${ }^{16}$ Standardising clinical assessments through checklists ensures that patients at risk of developing complications are identified early on, in turn allowing for a need-based treatment response and an ultimately improved quality of patient care. ${ }^{17}$ While financial rewards for primary care practitioners through the Quality and Outcomes Framework in England were found to be effective on some indicators such as emergency admissions, retention of primary practitioners, and also improved IT and data collection, they had no impact on mortality rates and other performance measures. ${ }^{18}$ Based on this evidence, ${ }^{19}$ LMICs should consider carefully the aims and underlying theories prior to adopting incentive schemes. However, for the past decade, performance-based finance schemes have been introduced widely across LMICs in sub-Saharan Africa, though with mixed results. ${ }^{20}$

\section{Priority setting: developing an evidence base to help}

To ensure that services are cost-effective and of high quality, NICE was set up as a government-funded independent authority in 1999, offering robust evidencebased guidance and recommendations on the adoption of cost-effective care, specifically: on the best practice treatment of specific conditions; on the use of medicines; on public health and social care; and on safe staffing levels in providers. NICE guidance is mandatory in some areas, and its use is assessed through analysis of national audit or disease registry data that is government funded. For new medicines, NICE assesses against an explicit cost-effectiveness threshold and makes recommendations. This way rationing decisions for expensive new drugs have a strong empirical evidence base, and this helps providers and policy makers who often face high-pressure from groups demanding high-cost treatments of uncertain or seemingly marginal benefit.

Population need varies by country, making it impossible to recommend a one-size-fits-all strategy, and priority setting should be based on evidence to avoid neglecting important health areas, or prioritising other areas simply because they are high profile. ${ }^{21}$ Yet, for many LMICs, there is benefit in borrowing analysis from NICE and other similar bodies internationally to help set priorities. A good example is the recent national Standard Treatment Guidelines on Diabetic Foot based on NICE guidelines published in India. ${ }^{22}$ At present, only a few LMICs have functioning priority setting institutions, such as the Health Intervention and Technology Assessment
Program in Thailand and CONITEC in Brazil, while a number of others such as China, India and the Philippines are moving in this direction. ${ }^{23-25}$ LMICs can learn and borrow from NICE, for example, through the International Decision Support Initiative. ${ }^{26}$

\section{Target setting and monitoring for enhanced performance}

The NHS over the years has invested in large datasets routinely collected to monitor the quality of care and performance of providers. Performance of existing healthcare services can be improved by setting national performance targets, in collaboration with clinicians and patients, with robust evidence, clear accountability and a wide set of metrics as a prerequisite for target success. ${ }^{27}$ For example, introducing national performance targets in conjunction with other initiatives resulted in a rapid and sustained reduction in healthcare-associated infections.

However, the impact and cost-effectiveness of NHS targets has been controversial for several reasons: it has resulted in some unintended consequences such as inefficient behaviours to meet targets, a sense of being 'blamed and shamed' on the part of institutional and individual providers, and adverse effects on care not covered by the target. ${ }^{28}$ However, the global literature shows some positive effect of measurement and public reporting of performance across countries where it has been implemented. ${ }^{29} 30$

Pay-for-performance can be used within the wider healthcare system to improve quality of care, such as in NHS primary care through the financial incentive to report and perform clinical assessments, and also in secondary care through targeted hospital performance measures like readmission rates. ${ }^{31-33}$ As with target setting, unintended consequences and perverse outcomes need to be anticipated and closely monitored, presenting big implementation challenges for LMICs. ${ }^{34}$ The lesson learnt from the NHS is that governments in LMICs should be careful in opting for introducing targets and pay-for-performance schemes, a perspective supported by a recent review recommending their abolishment due to the associated high-level of resource use. ${ }^{34}$ For example, the operating cost of a model introduced in Burkina Faso was found to account for $30 \%$ of the overall cost of the scheme, which arguably could result in greater benefit if invested elsewhere.

\section{Integrated, coordinated care}

A policy thrust over the past 4 years has been to boost growth in investment in primary care over hospital care and to encourage the NHS to coordinate care more, in particular between the separate sectors of hospital and primary care on the one hand, and NHS healthcare and local social care on the other. The key strategy here has been set out in the NHS Five Year Forward View, ${ }^{35}$ and the policy has been to incentivise providers to work more closely with one another, share information about patients, in order to manage their care in a 
more coordinated way, improve wellness, and to reduce the risk of costly hospitalisation. Case integration is also widespread across other parts of Europe (ie, Sweden) ${ }^{36}$ and North America (ie, Accountable Care Organisations in the USA) ${ }^{37}$ as an attempt to curb cost growth and increase value of the care provided, and lessons could be learnt from their experience. The strategy in the English NHS is a well-structured variant that LMICs might find useful, in particular the priority to boost investment in primary care and give incentives to hospitals to work to reduce avoidable admissions.

Many LMICs still suffer from a high prevalence of infectious diseases and together with help of donor funding have developed strategies to improve capacity to deliver healthcare over the past decade. Extending existing delivery platforms such as community services employed for HIV and malaria testing to include services for detection and treatment of NCDs could provide an opportunity for health systems to improve patient care and also to alleviate pressure from hospital services. Ensuring integration between a functioning primary care system and disease control programme was found to be effective in improving population health in Costa Rica. ${ }^{38}$

\section{Regulation of quality}

The NHS has a sophisticated system of regulation-of individual professionals and also of providers of care. In England, the Care Quality Commission (CQC) monitors, inspects and regulates most health and social care services. Findings are made available publicly, including ratings for each provider, to help people choose care based on direct provider comparisons. Covering about 8000 primary care practices, 17000 providers of social care and 250 NHS hospitals, as well as the relatively small number of non-NHS healthcare facilities, the CQC's work is extensive, and it has had a significant impact on providers to increase the quality of care. The CQC is funded in part through government and in part through mandatory fees charged to the providers being regulated, and providers are not allowed to operate unless they are regulated by the CQC. In many other countries, there are government or private bodies that use routinely collected data to rate providers on the quality of care. What is unusual about the CQC is that it inspects providers using a systematic method, therefore picking up information that cannot be gleaned through using routinely collected quantitative data alone and is independent of vested interests. It also uses sophisticated data-driven methods to identify providers at high risk to prioritise its inspection programme, and importantly, inspectors also include patients-'experts by experience'.

Although every healthcare system will have aspects of care that are flawed, objective and routinely performed assessments are an important aspect of controlling and ensuring the provision of good quality healthcare services. While quantitative assessments to determine providers in need of inspections through the use of routine data can be affected by gaming, having a system that combines both quantitative and qualitative inspections across a wide range of quality indicators will help limit abuse of the system. LMICs might find it useful to adopt a similar structure to the CQC in England, but they should be aware that any inspection system requires substantial financial investments. Several regulatory processes to examine the quality of healthcare facilities exist across LMICs. For instance, Rwanda introduced quality check lists completed by health centres on a monthly basis and verified through unannounced quarterly inspections by members of the district health management. ${ }^{39}$

\section{Investing in people}

Ensuring that healthcare systems are equipped with the right skill-mix is fundamental to providing efficient and sustainable healthcare. In the past, the NHS benefitted and encouraged migration of high-skilled medical professionals, but in light of rising demands and political uncertainty, not least following the referendum to leave the European Union, has faced challenges in recruiting and retaining the required number of clinical staff.

One way to increase productivity within the existing workforce is task-shifting where traditional doctor roles are reassigned to other staff, for example, supported with the use of decision aids available through technology. For example, Clinical Nurse Specialists in the NHS have demonstrated many benefits: reduction in emergency bed days, follow-up appointments, primary care visits and medication errors, as well as high levels of patient satisfaction. Moreover, Emergency Care Practitioners trained to triage, diagnose and treat common emergencies make safe decisions and reduce admissions to hospital. Taskshifting is a cost-effective way to address human resource challenges $^{40}$ and may also entail patient empowerment to improve self-care abilities. Ideally, investment in technology should prioritise where technology can support this type of task-shift to staff with lower levels of formal qualifications, or even to patients themselves.

It is well recognised that many LMICs experience dramatic staff shortages and significant problems with staff retention in rural areas. This has resulted in implementation problems of planned quality improvement interventions, driven by factors such as inadequate training resources, unsatisfactory working conditions and an imbalance between urban and rural staffing levels. To tackle this human resource crisis, many LMICs have developed strategies including the National Human Resources for Health Strategic Plan by the Zambian Ministry of Health ${ }^{41}$ or the Afghanistan National Health Workforce Plan. ${ }^{42}$ Most of the proposed initiatives refer to improved professional development opportunities and financial incentives for staff retention in rural areas, but based on experience from the NHS, there is substantial scope for task-shifting within the existing workforce, which can create an environment that is conducive to staff and patient empowerment. 


\section{CONCLUSION}

Achieving high-quality UHC in LMICs remains a challenging task, and while governments have shown clear political willingness to reach this goal by 2030, many obstacles will have to be overcome. Learning from experiences of functioning UHCs can provide useful insights on how to address existing challenges. This article proposes the copying of principles and values, rather than direct transfers of NHS policies.

Securing a high-quality UHC requires strong political leadership, and at times where UHC provided by the NHS was under doubt in the late 1990s, key policies such as a notion of clinical governance, NICE and the predecessor of the CQC were introduced with a focus on improving quality and reducing variation. ${ }^{43}$ It is this timeframe that might prove particularly useful and inspirational to LMICs, as it shows how leadership and drive to renew the value of UHC led to an unprecedented level of innovation. As political leaders, and finance and health ministries in LMICs negotiate their path forwards, this analysis paper gives some points of learning from the NHS, a healthcare system that has provided high-quality UHC for over 70 years.

Contributors RF and $\mathrm{KC}$ had the idea for this article. All other authors contributed substantially to the write up of this article and approved the final version.

Funding The authors have not declared a specific grant for this research from any funding agency in the public, commercial or not-for-profit sectors.

Competing interests None declared.

Patient consent for publication Not required.

Provenance and peer review Not commissioned; externally peer reviewed.

Data sharing statement No additional data are available.

Open access This is an open access article distributed in accordance with the Creative Commons Attribution Non Commercial (CC BY-NC 4.0) license, which permits others to distribute, remix, adapt, build upon this work non-commercially, and license their derivative works on different terms, provided the original work is properly cited, appropriate credit is given, any changes made indicated, and the use is non-commercial. See: http://creativecommons.org/licenses/by-nc/4.0/

\section{REFERENCES}

1. Senkubuge F, Modisenyane M, Bishaw T. Strengthening health systems by health sector reforms. Glob Health Action 2014;7:23568-7.

2. Cs W, Paulsen E, Lewin S. Financial arrangements for health systems in low-income countries : an overview of systematic reviews. Cochrane Database Syst Rev 2017:1-76.

3. Barker P. Making universal health coverage whole: adding quality as the fourth dimension. Institute for Healthcare Improvement, 2016.

4. Barik D, Arokiasamy P. Rising health expenditure due to noncommunicable diseases in India: an outlook. Front Public Health 2016;4:1-8.

5. Dalal S, Beunza JJ, Volmink J, et al. Non-communicable diseases in sub-Saharan Africa: what we know now. Int J Epidemiol 2011;40:885-901.

6. Robertson R, 2017. Public satisfaction with the NHS and social care in 2016: results and trends from the British Social Attitudes survey. Available from: https://www.kingsfund.org.uk/publications/publicsatisfaction-nhs-2016

7. Robertson R, Appleby J, Evans H, 2018. Public satisfaction with the NHS and social care in 2017. Available from: http://www.who.int/ entity/bulletin/volumes/94/6/15-155721.pdf

8. Reich MR, Harris J, Ikegami N, et al. Moving towards universal health coverage: lessons from 11 country studies. Lancet 2016;387:811-6.
9. OECD. OECD reviews of health care quality: United Kingdom 2016 : raising standards. Paris: OECD, 2016.

10. Molloy A, Martin S, Gardner T, et al. A clear road ahead. London, England, 2016.

11. Webber L, Chalkidou K, Morrow S. What are the best societal investments for improving people's health? BMJ 2018;3377:k3377.

12. Public Health Health, 2017. Local tobacco control profiles: indicators at a glance February 2017. Available from: https://www.gov.uk/ government/uploads/system/uploads/attachment_data/file/496491/ LTCP At_a_Glance_Feb_2016.pdf

13. Allen LN, Pullar J, Wickramasinghe K, et al. Are WHO "best buys" for non-communicable diseases effective in low-income and lowermiddle-income countries? A systematic review. Lancet Glob Health 2017;5:S17.

14. Matanje Mwagomba BL, Nkhata MJ, Baldacchino A, et al. Alcohol policies in Malawi: inclusion of WHO "best buy" interventions and use of multi-sectoral action. BMC Public Health 2018;18:957.

15. Silva AC, Bortolini GA, Jaime PC. Brazil's national programs targeting childhood obesity prevention. Int J Obes Suppl 2013;3:S9-S11.

16. NHS Employers, BMA, NHS England, 2015. 2015/16 General Medical Services (GMS) contract Quality and Outcomes Framework (QOF). Available from: http://www.nhsemployers.org/ / media/Employers/Documents/Primary\%20care\%20contracts/QOF/ 2015\%20-\%2016/2015-16\%20QOF\%20guidance\%20documents. pdf

17. Mendu ML, Schneider LI, Aizer AA, et al. Implementation of a CKD checklist for primary care providers. Clin J Am Soc Nephrol 2014;9:1526-35.

18. Forbes LJ, Marchand C, Doran T, et al. The role of the Quality and Outcomes Framework in the care of long-term conditions: a systematic review. Br J Gen Pract 2017;67:e775-84.

19. Scott A, Sivey $P$, Ait Ouakrim D, et al. The effect of financial incentives on the quality of health care provided by primary care physicians. Cochrane Database Syst Rev 2011;9:1-59.

20. De Allegri M, Bertone MP, McMahon S, et al. Unraveling PBF effects beyond impact evaluation: results from a qualitative study in Cameroon. BMJ Glob Health 2018;3:e000693.

21. Glassman A, Chalkidou K, Giedion U, et al. Priority-setting institutions in health: recommendations from a center for global development working group. Glob Heart 2012;7:13-34.

22. Mehndiratta A, Sharma S, Gupta NP, et al. Adapting clinical guidelines in India-a pragmatic approach. BMJ 2017;359:j5147.

23. Chalkidou K, Glassman A, Marten R, et al. Priority-setting for achieving universal health coverage. Bull World Health Organ 2016;94:462-7.

24. Downey LE, Mehndiratta A, Grover A, et al. Institutionalising health technology assessment: establishing the Medical Technology Assessment Board in India. BMJ Glob Health 2017;2:e000259.

25. Tantivess S, Chalkidou K, Tritasavit N, et al. Health Technology Assessment capacity development in low- and middle-income countries: experiences from the international units of HITAP and NICE. F1000Res 2017;6:2119.

26. IDSI, 2018. The International decision support innitiative. Available from: http://www.idsihealth.org [Accessed 7 Mar 2018].

27. Berry N, Gardner T, Anderson I. On targets : how targets can be most effective in the English NHS, 2015.

28. National Audit Office, 2009. Reducing healthcare associated infections in hospitals in England. Available from: http://www.nao. org.uk/wp-content/uploads/2009/06/0809560.pdf\%5Cnhttp://www. nao.org.uk/report/reducing-healthcare-associated-infections-inhospitals-in-england/

29. Björkman Nyqvist M, de Walque D, Svensson J. Experimental evidence on the long-run impact of community-based monitoring. Am Econ J Appl Econ 2017;9:33-69.

30. McNamara P. Provider-specific report cards: a tool for health sector accountability in developing countries. Health Policy Plan 2006;21:101-9.

31. Friebel R, Hauck K, Aylin P, et al. National trends in emergency readmission rates: a longitudinal analysis of administrative data for England between 2006 and 2016. BMJ Open 2018;8:e020325-10.

32. Friebel $R$, Steventon $A$. The multiple aims of pay-for-performance and the risk of unintended consequences. BMJ Qual Saf 2016;25:827-31.

33. Friebel R, Dharmarajan K, Krumholz HM, et al. Reductions in Readmission Rates Are Associated With Modest Improvements in Patient-reported Health Gains Following Hip and Knee Replacement in England. Med Care 2017:55:834-40.

34. Paul E, Albert L, Bisala BN, et al. Performance-based financing in low-income and middle-income countries: isn't it time for a rethink? BMJ Glob Health 2018;3:e000664. 
35. NHS England, 2014. Five year forward view. Available from: http:// www.england.nhs.uk/wp-content/uploads/2014/10/5yfv-web.pdf [Accessed 13 May 2015].

36. Bäck MA, Calltorp J. The Norrtaelje model: a unique model for integrated health and social care in Sweden. Int $J$ Integr Care 2015;15:1-15.

37. Shortell S, Addicott R, Walsh N, et al. Accountable care organisations in the United States and England 2014.

38. Unger JP, De Paepe P, Buitrón R, et al. Costa Rica: achievements of a heterodox health policy. Am J Public Health 2008;98:636-43.

39. Ergo A, Paina L, Morgan L, 2012. Creating stronger incentives for high-quality health care in low-and middle-income countries. Available from: https://pdf.usaid.gov/pdf_docs/pnady966.pdf\%
5Cnhttp://www.mchip.net/sites/default/files/QoC\%20and\%20PBI_ Full\%20report Final.pdf

40. Seidman G, Atun R. Does task shifting yield cost savings and improve efficiency for health systems? A systematic review of evidence from low-income and middle-income countries. Hum Resour Health 2017;15:1-13.

41. Ministry of Health Zambia. National human resources for health strategic plan 2011 - 2016, 2011.

42. Shahir I, Homayee S, Fitzwarryne C, et al. Planning and reform of human resources for health in Afghanistan. AFJPH 2012;1:34-41.

43. The Department of Health. The new NHS modern. dependable, 1997. 